Article

\title{
Simulation Study on Centrifugal Spray Evaporation Characteristics and Process Optimization of Desulfurization Wastewater
}

\author{
Ning Zhao ${ }^{1}$, Yongxin Feng ${ }^{1}$, Debo $\mathrm{Li}^{1}$ and Zongkun $\mathrm{Li}^{2, *}$ \\ 1 China Southern Power Grid Technology Co., Ltd., Guangzhou 510080, China; 15088050825@163.com (N.Z.); \\ yongxingf@126.com (Y.F.); ldbyx@126.com (D.L.) \\ 2 School of Electric Power, South China University of Technology, Guangzhou 510640, China \\ * Correspondence: 202021014717@mail.scut.edu.cn
}

Citation: Zhao, N.; Feng, Y.; Li, D.;

$\mathrm{Li}, \mathrm{Z}$. Simulation Study on

Centrifugal Spray Evaporation

Characteristics and Process

Optimization of Desulfurization

Wastewater. Coatings 2021, 11, 837.

https://doi.org/10.3390/

coatings 11070837

Academic Editor: Rahmat Ellahi

Received: 2 June 2021

Accepted: 8 July 2021

Published: 12 July 2021

Publisher's Note: MDPI stays neutral with regard to jurisdictional claims in published maps and institutional affiliations.

Copyright: (c) 2021 by the authors. Licensee MDPI, Basel, Switzerland. This article is an open access article distributed under the terms and conditions of the Creative Commons Attribution (CC BY) license (https:// creativecommons.org/licenses/by/ $4.0 /)$.

\begin{abstract}
As an advanced treatment of desulfurization wastewater, centrifugal spray drying technology, which can achieve a zero liquid discharge target, has attracted wide attention and great interest in recent years. However, the results of previous studies were based on the laboratory-scale centrifugal spray dryer. In order to study the evaporation characteristics of desulfurization wastewater and the parameter optimization of the dryer, the evaporation model of wastewater droplets was established. The effects of parameters such as the angle of the deflectors, gas-liquid ratio and atomizer speed on droplet evaporation were studied by numerical simulation. The results show that with the increase in the angle of the deflectors, the swirl effect of flue gas flow field is more obvious and the time and axial distance required for the complete evaporation of the droplets are shorter. Reducing the gas-liquid ratio will make the average evaporation time longer. Moreover, a higher atomizer speed is helpful for the evaporation of the droplets. The optimum gas-liquid ratio and rotational speed are found to be $9300 \mathrm{~m}^{3} / \mathrm{Nm}^{3}$ and $16,000 \mathrm{rpm}$, respectively.
\end{abstract}

Keywords: centrifugal spray; desulfurization wastewater; flow field; numerical simulation; zero liquid discharge

\section{Introduction}

With the development of industrialization and urbanization, people's demand for electricity is increasing [1,2]. China's energy structure is dominated by coal, which will produce pollutants, such as smoke, dust, sulfur oxides and other pollutants, when burning [3]. A large amount of sulfur oxides (including $\mathrm{SO}_{2}$ and $\mathrm{SO}_{3}$ ) is an important cause of acid rain and smog, which seriously endanger human health [4-6]. At present, common flue gas desulfurization (FGD) processes include dry, wet and semi-dry methods, among which the wet limestone-gypsum FGD desulfurization technology is the most widely used $[7,8]$. In order to maintain the material balance in the slurry circulation system of an FGD device, prevent the chlorine concentration in the flue gas from exceeding the specified value and ensure gypsum quality a certain amount of wastewater must be discharged from the system. However, desulfurization wastewater contains various suspended solids, supersaturated sulfites, sulfates and heavy metals [9]. If not handled properly, it will cause serious secondary pollution to the environment. For this reason, China has begun to increase the treatment of desulfurization wastewater and put forward zero liquid discharge (ZLD) processes for coal-fired power plants.

Wastewater treatment is an important part of environmental protection and it has been developed at the technical level [10-12]. Traditional crystallization and evaporation technology covers a large area and high cost, which gradually limits its application $[13,14]$. Therefore, ZLD technology has been developed and applied to a certain extent $[15,16]$. Recently, spray drying technology, an advanced ZLD process of desulfurization wastewater, 
has received more attention [17]. One technical approach is to spray wastewater into the flue between the air preheater and electrostatic precipitator and use the preheating and evaporation of the flue gas $[9,18]$. Then, the crystalline salt and dust are captured by the precipitator. This method is simple and low in cost, but there are some problems, such as the flue wall being susceptibly corroded and the evaporation efficiency being affected by boiler load [19]. Another way is to introduce partial hot flue gas from the upstream of the air preheater into the centrifugal spray dryer. The wastewater is atomized into small droplets through the centrifugal atomizer and instantaneously evaporated due to absorbing the waste heat of flue gas. After the droplets are completely evaporated, the dry matter separated from the FGD wastewater is crystallized into solid particles and captured in the electrostatic precipitator or the follow-up dust collector, as shown in Figure 1 [20]. Due to high evaporation efficiency and small impact on downstream equipment, the method has good application prospects [21,22].

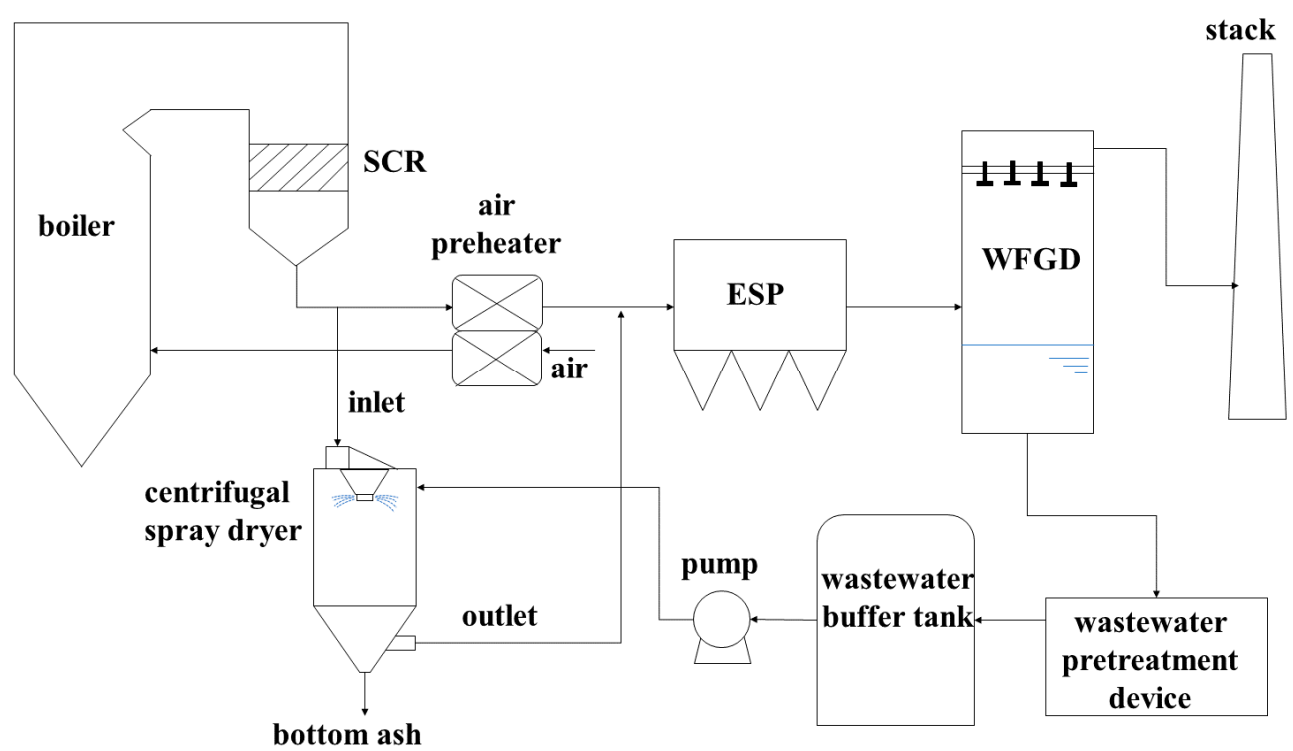

Figure 1. Typical treatment process of spraying FGD wastewater in centrifugal spray dryer for evaporation.

Many researchers have studied the evaporation characteristics of droplets by means of theoretical calculations and experimental methods. Ceidk et al. [23] proposed an empirical relationship between the average droplet diameter and gas flow. They found that, when the liquid flow rate is constant, the mean droplet diameter decreases as the gas flow rate increases, but the size distribution is basically unchanged. Liang et al. [24] studied the effects of different operating parameters, such as temperature increasing rate and droplet volume, on the evaporation and crystallization characteristics of desulfurization wastewater droplets. It was found that increasing the heating rate can improve the evaporation and crystallization efficiency of the droplets simultaneously, while an excessively large droplet volume will cause the crystallization rate to decrease. Kim et al. [25] investigated the synergistic effect of ambient pressure and temperature on the evaporation time of the droplets. The results show that, when the temperature is higher, the evaporation time has a negative correlation with environmental pressure. However, the situation is reversed when the temperature is below a certain critical value.

Considering the difficulty in obtaining detailed flow field, temperature field and humidity field data through experimental methods, some scholars have used computational fluid dynamics (CFD) to numerically simulate the spray drying process and give various evaporation models [26-29]. Gradinger et al. [30] established a zero-dimensional droplet evaporation model and numerical solution algorithm for spray simulation, which are in line with the experimental results in a wide temperature range. Ma et al. [31] performed 
a numerical simulation on the evaporation process of desulfurization wastewater and found that increasing flue gas temperature, as well as reducing atomized particle size, is beneficial to the evaporation of wastewater, while the effect of flue gas flow rate on this can be ignored. Zhang et al. [32] used the DPM model to investigate the evaporation process of a droplet group in a centrifugal spray dryer. They clarified that the droplets experienced multiple vortex motions in the tower, which increased the evaporation rate. Moreover, most of the droplets evaporate at a constant temperature at the wet bulb temperature. Wilson and Javed et al. [33,34] found that the use of rotating airflow in the spray dryer can increase the rate of heat and mass transfer between gas and liquid that directly determines the evaporation time and evaporation distance of the droplet.

Although there have been many reports, they are mainly focused on laboratory-scale spray drying research and actual model size has an important influence on the results. The evaporation rate of desulfurization wastewater is closely related to the flow field distribution of flue gas, which depends on the structure of flue gas distributor in the dryer. In addition, some operating parameters of the dryer have an important influence on the heat and mass transfer behavior between the droplets and flue gas. In this work, wastewater evaporation was carried out in the centrifugal spray dryer for a coal-fired power plant, rather than in a laboratory-scale one. Different from the previous experimental methods, CFD technology is used to perform numerical analysis on the dryer and more detailed data can be obtained. Moreover, the influence of structural parameters and operating parameters, including the angle of the deflectors in the hot air distributor, the gas-liquid ratio and the rotational speed of the atomizer on the droplet evaporation characteristics, is studied, which can provide a theoretical guide for the design and optimization of evaporation equipment in the flue.

\section{Numerical Method}

\subsection{Study Object}

A centrifugal spray dryer for desulfurization wastewater installed in the bypass flue of a $330 \mathrm{MW}$ coal-fired unit is considered as the research model of CFD in this study, which is shown in Figure 2. It has a diameter of $7.2 \mathrm{~m}$ and a height of $11.7 \mathrm{~m}$, including the gas distributor and tower body. The gas distributor is mainly composed of the gas inlet, volute, inner flow channel, outer flow channel and several deflectors and the atomizer is located directly below the gas distributor. On the one hand, the flue gas enters into the volute from the inlet to generate rotary flow. Then, it enters into the inner and outer flow channels with 24 deflectors installed respectively. These deflectors guide the flue gas, making it spiral down into the tower body. On the other hand, the atomizer rotates at a high speed and the desulfurization wastewater is thrown out of the orifice channel by centrifugal force, thereby atomizing into droplets. The angle $\theta$ of the inner and outer deflectors can be changed, as shown in Figure 3. Among them, the axis is parallel to the tapered wall, where the deflector is located. Because of its complex structure, the model was established by the software ANSYS ICEM V19.0, using unstructured tetrahedral mesh. Due to the large velocity gradient in the hot air distributor and atomizer, a local mesh refinement (increasing the mesh number) was carried out in the relevant area to improve the calculation accuracy, as shown in Figure 4. 


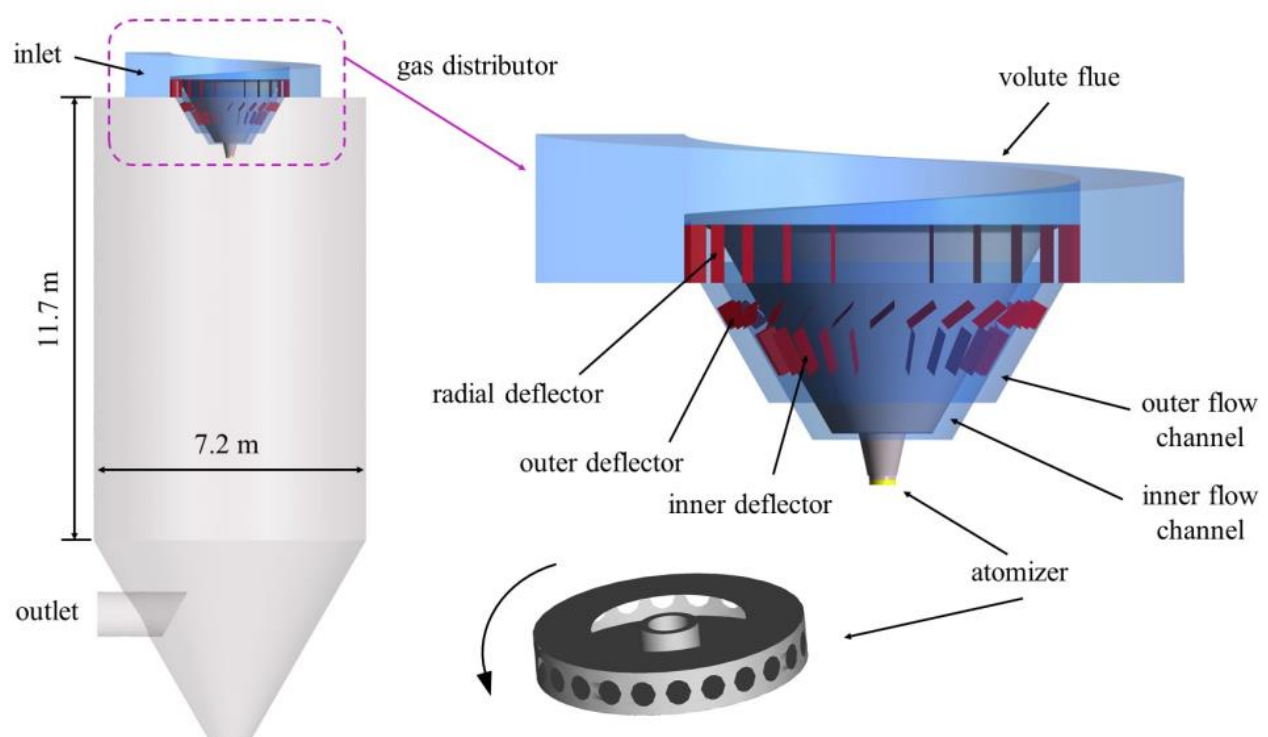

(a)

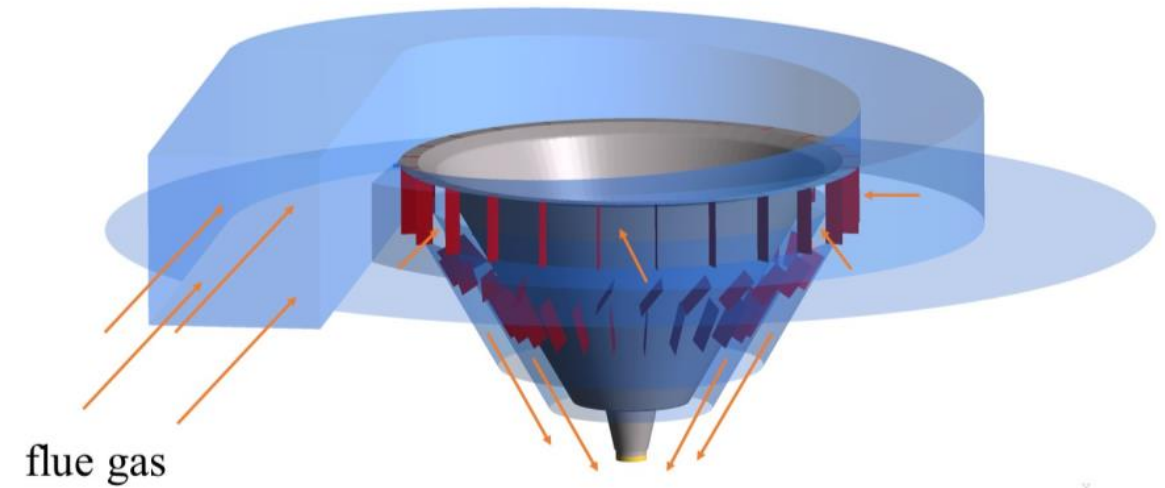

(b)

Figure 2. Schematic diagram of centrifugal atomization dryer: (a) dryer structure; (b) gas flow direction.

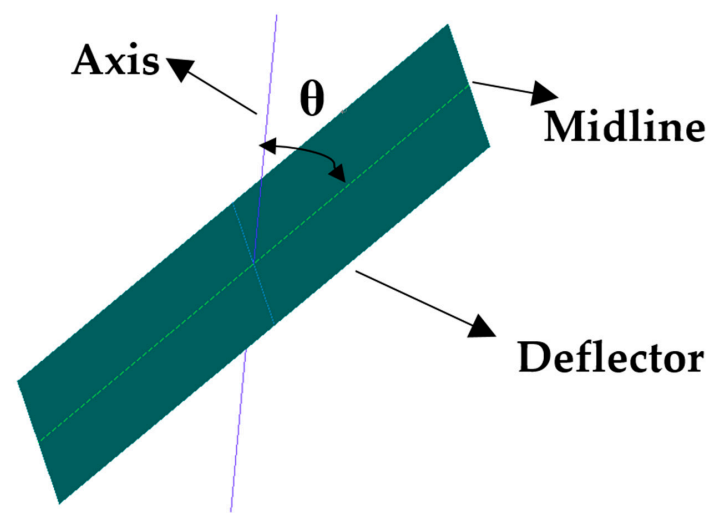

Figure 3. Cont. 


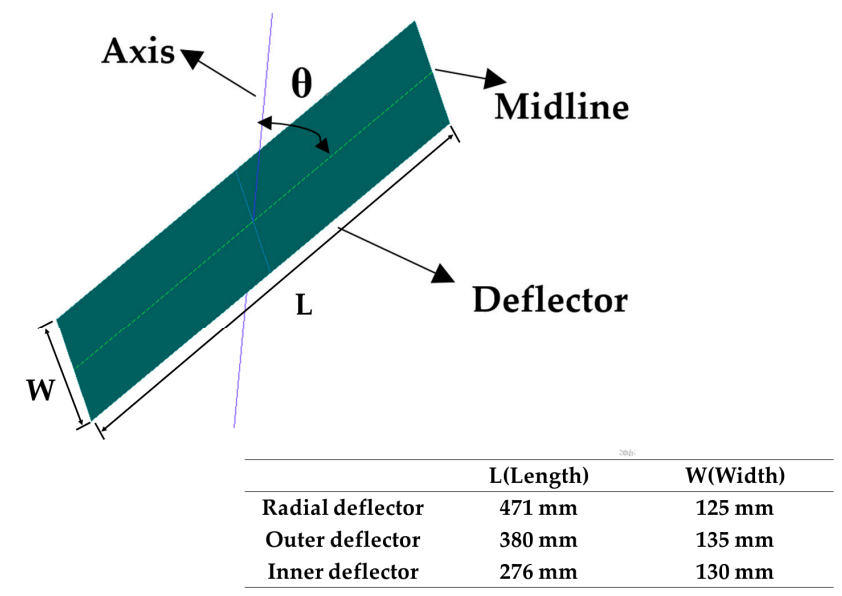

Figure 3. Schematic diagram of the angle of inner and outer deflectors: axis, parallel to the tapered wall where the deflector is located; $\theta$, the angle between axis and midline.

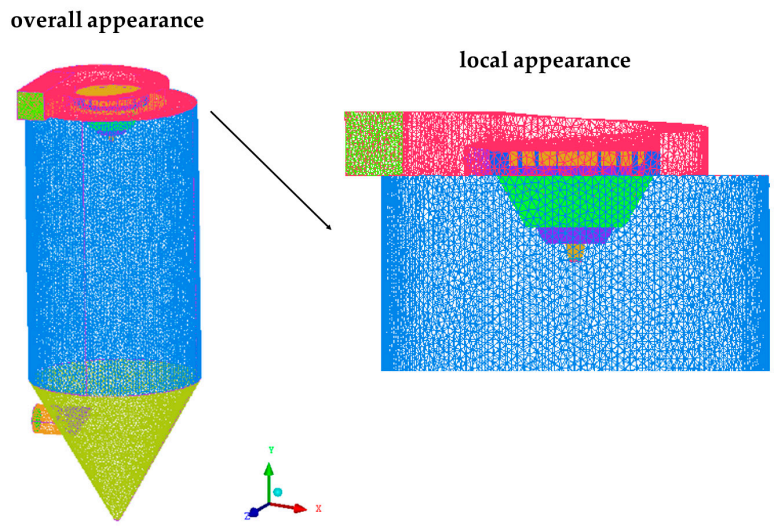

Figure 4. Mesh scheme applied to the centrifugal spray dryer.

The mesh-independent verification of the computational grid was required. In this work, eight mesh numbers (2,000,000 cells, 2,500,000 cells, 3,000,000 cells, 3,500,000 cells, $4,000,000$ cells, 4,500,000 cells, 5,000,000 cells and 5,500,000 cells) were simulated to record the changes of outlet temperature. As shown in Figure 5, a mesh dependency test was conducted to determine the appropriate mesh number. The results indicated that the mesh used in this study $(4,500,000$ cells $)$ was mesh-independent.

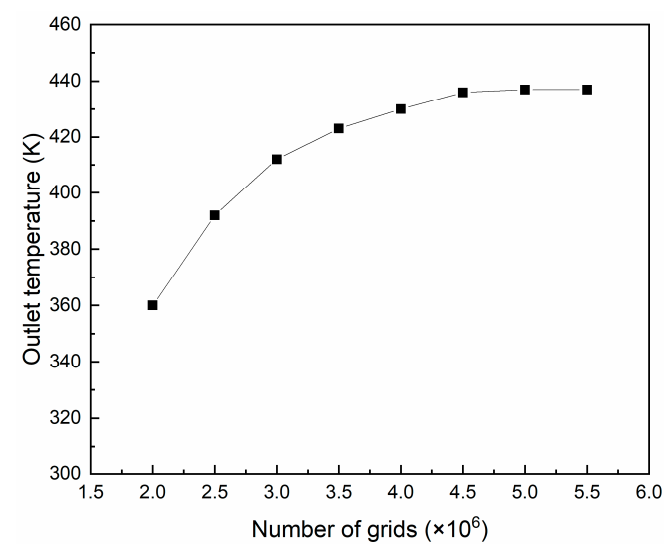

Figure 5. Mesh-independent verification of the centrifugal spray dryer. 


\subsection{Mathematical Model}

The atomization drying of desulfurization wastewater involves the heat and mass transfer process between gas phase and liquid phase. Since the drying tower generally operates under slight negative pressure, the gas density does not change much, so the flue gas can be regarded as an incompressible ideal gas. The governing equation is shown below.

Continuity equation:

$$
\frac{D \rho_{g}}{D t}+\rho_{g}\left(\nabla \cdot \overrightarrow{u_{g}}\right)=0
$$

Momentum equation:

$$
\rho_{g} \frac{D \overrightarrow{u_{g}}}{D t}=\rho_{g} f_{i}+\nabla \cdot p_{i j}
$$

Energy equation:

$$
\rho_{g} \mathcal{c}_{v} \frac{D T}{D t}=k_{g} \nabla^{2} T+\varphi
$$

Component transport equation:

$$
\frac{\partial\left(\rho_{g} Y_{s}\right)}{\partial t}+\frac{\partial\left(\rho_{g} u_{g} Y_{s}\right)}{\partial x_{i}}=\frac{\partial}{\partial x_{i}}\left(D \rho_{g} \frac{\partial Y_{s}}{\partial x_{i}}\right)+\omega_{s}+S_{Y_{s}}
$$

Unlike flue gas, the momentum equation of desulfurization wastewater is solved by the Lagrange method. Since the gas density is much smaller than the droplet, the virtual mass force, Saffman lift force, thermophoretic force and Brownian force are small, so the above forces can be ignored and only the drag force and gravity on the droplet are considered. Then, the momentum equation can be described by Equation (5):

$$
\frac{d u_{p}}{d t}=F_{D}\left(u_{g}-u_{p}\right)+\frac{g\left(\rho_{p}-\rho_{g}\right)}{\rho_{p}}
$$

where $F_{D}$ is drag force, $u_{g}$ and $u_{p}$ are the velocity of the gas phase and the velocity of droplet particles, respectively and $\rho_{g}$ and $\rho_{p}$ are the density of the gas phase and the density of the droplets. Among them, $F_{D}$ can be expressed by Equation (6):

$$
F_{D}=\frac{18 \mu_{g}}{\rho_{p} d_{p}^{2}} \frac{C_{D} R e_{p}}{24}
$$

where $\mu_{g}$ is the dynamic viscosity, $C_{D}$ is the drag coefficient and $R e_{p}$ is the relative Reynolds number of gas and liquid.

Due to the large temperature difference, the droplets are heated by the flue gas and the temperature rises rapidly. After reaching the boiling point, a strong heat and mass transfer process occurs with the flue gas. After the droplets are completely evaporated, the water vapor is mixed with flue gas and the temperature gradually reaches the equilibrium point. This process is divided into three stages:

(1) When the liquid temperature is lower than the evaporation temperature, the droplet only conducts the heat transfer process with the flue gas and the quality does not change. Regardless of radiation heat transfer, the heat transfer equation, at this time, is:

$$
m_{p} c_{p} \frac{d T_{p}}{d t}=h A_{p}\left(T_{g}-T_{p}\right)
$$

where $m_{p}, c_{p}, T_{p}$ and $A_{p}$ are the mass, specific heat capacity at constant pressure, temperature and surface area of droplet particles, respectively, $T_{g}$ is the temperature of the incoming flue gas and $h$ indicates the convective heat transfer coefficient.

(2) When the liquid temperature is greater than the evaporation temperature and less than the boiling temperature, the heat absorbed by the droplet from the flue gas is used 
for the temperature increase and the evaporation process at the same time. Under these circumstances, the heat transfer equation is:

$$
m_{p} c_{p} \frac{d T_{p}}{d t}=h A_{p}\left(T_{g}-T_{p}\right)+\frac{d m_{p}}{d t} h_{l g}
$$

where $h_{l g}$ is the latent heat of liquid.

The evaporation rate of the droplet is related to the concentration gradient between gas and liquid, which is determined by Equation (9):

$$
N_{i}=k_{c}\left(C_{i, s}-C_{i, g}\right)
$$

where $N_{i}$ is the steam molar flux, $k_{c}$ is the mass transfer coefficient and $C_{i, s}$ and $C_{i, g}$ are the vapor concentration on the droplet surface and in the main gas stream, respectively. Furthermore, $k_{c}$ is determined by the Nusselt number and its value adopts the recommended value given by the literature [35]:

$$
N u=\frac{k_{c} d_{p}}{D_{i, m}}=2+0.6 R e_{d}^{1 / 2} S c^{1 / 3}
$$

(3) When the liquid temperature reaches boiling temperature, the unevaporated droplets and the flue gas undergo a strong heat and mass transfer process and the boiling rate equation is as follows:

$$
\frac{d\left(d_{p}\right)}{d t}=\frac{4 k_{g}}{\rho_{p} c_{p, g} d_{p}}\left(1+0.23 \sqrt{R e_{p}}\right) \ln \left[1+\frac{c_{p, g}\left(T_{g}-T_{p}\right)}{h_{l g}}\right]
$$

where $R e_{p}$ is the Reynolds number of the liquid droplet relative to the gas motion.

\subsection{Numerical Procedures}

Because the pressure change in the dryer is small and the time also has little effect on the flow field change, the pressure solver is selected for steady-state simulation. In order to reflect the influence of the high-speed and complex vortex on the gas flow, the realizable $\mathrm{k}-\varepsilon$ model was selected for turbulence equation and the standard wall function was used [36]. The component transport model was activated to simulate the change of the concentration of each component when the droplets were evaporating. The discrete phase was described using the DPM model based on the Lagrange coordinates. Since turbulence has an important influence on the trajectory of the droplets, a random trajectory model is used to describe the turbulent diffusion of the droplets. First, carry out continuous phase simulation until convergence; then, activate the DPM discrete model and iterate through the mutual coupling of the continuous phase and the discrete phase until convergence.

\section{Numerical Conditions}

\subsection{Boundary Conditions and Operating Parameters}

For the continuous phase, velocity inlet and outflow conditions were adopted. Because the outer walls of the spray dryer and flue are spread with a thicker insulation layer, resulting in little thermal loss of flue gas, the wall conditions were set to be adiabatic. Since the incompletely evaporated desulfurization wastewater droplets stick to the wall surface and cause corrosion problems, the wall surface conditions for trapping the droplets are set to monitor the occurrence of this situation. Desulfurization wastewater contains a variety of ions, such as $\mathrm{Ca}^{2+}, \mathrm{Mg}^{2+}, \mathrm{Na}^{+}, \mathrm{Cl}^{-}$and $\mathrm{SO}^{2-}$, and there are, mostly, $\mathrm{Na}^{+}$and $\mathrm{Cl}^{-}$. Therefore, a $\mathrm{NaCl}$ solution is used to represent it. Gas-liquid ratio is defined as the ratio of liquid volume to gas volume in standard state. The saturated vapor pressure of salt solution is lower than that of pure water, making it more difficult to evaporate. In this paper, the saturated vapor pressure of the $\mathrm{NaCl}$ solution was obtained according to the literature [37]. The detailed operating parameters of the design case are shown in Table 1. 
Table 1. Parameters of design case.

\begin{tabular}{ccc}
\hline Fluid & Parameter & Value \\
\hline & Velocity $(\mathrm{m} / \mathrm{s})$ & 13.25 \\
& Volume flow $\left(\mathrm{Nm}^{3} / \mathrm{h}\right)$ & 30,000 \\
Tlue gas & Temperature $(\mathrm{K})$ & 613 \\
& Volume fraction of each component $(\%)$ & 3.00 \\
& $\mathrm{~N}_{2}$ & 75.26 \\
$\mathrm{O}_{2}$ & 13.60 \\
$\mathrm{CO}_{2}$ & 8.14 \\
\hline Desulfurization wastewater & $\mathrm{H}_{2} \mathrm{O}$ & $8 \mathrm{wt}^{\circ} \mathrm{NaCl} \mathrm{solution}$ \\
& component & 323 \\
& Temperature $(\mathrm{K})$ & 10,000 \\
& Gas-liquid ratio $\left(\mathrm{m}^{3} / \mathrm{Nm}^{3}\right)$ & 13,000 \\
& Rotational speed $(\mathrm{rpm})$ & 50 \\
\hline
\end{tabular}

\subsection{Reliability Verification to CFD Model}

To verify the reliability of the model, four different load conditions were simulated. Table 2 lists the actual operating parameters of each load. Table 3 shows the outlet temperature and $\mathrm{H}_{2} \mathrm{O}$ mass fraction from the simulation and actual measurement. Comparing the simulation results with the actual measurement results, it is found that the relative error is less than $5 \%$, which proves that the model has high reliability and is acceptable in engineering.

Table 2. Running parameters for each load.

\begin{tabular}{ccccc}
\hline Load/MW & $\begin{array}{c}\text { Volume Flow of } \\
\text { Flue Gas/(t/h) }\end{array}$ & $\begin{array}{c}\text { Inlet Flue Gas } \\
\text { Temperature/K }\end{array}$ & $\begin{array}{c}\text { Volume Flow of } \\
\text { Wastewater/(t/h) }\end{array}$ & $\begin{array}{c}\text { Inlet Wastewater } \\
\text { Temperature/K }\end{array}$ \\
\hline 250 & 18.31 & 600 & 1.2 & 323 \\
280 & 21.17 & 603 & 1.26 & 323 \\
330 & 19.98 & 599 & 1.33 & 323 \\
400 & 29.3 & 629 & 2.01 & 323 \\
\hline
\end{tabular}

Table 3. Outlet temperature (T) and outlet $\mathrm{H}_{2} \mathrm{O}$ mass fraction $(\mathrm{W})$ of measurement and simulation.

\begin{tabular}{ccccccc}
\hline Load/MW & $\begin{array}{c}\text { Measurement } \\
\text { T/K }\end{array}$ & $\begin{array}{c}\text { Simulation } \\
\text { T/K }\end{array}$ & $\begin{array}{c}\text { Relative } \\
\text { Error/\% }\end{array}$ & $\begin{array}{c}\text { Measurement } \\
\text { W/\% }\end{array}$ & $\begin{array}{c}\text { Simulation } \\
\text { W/\% }\end{array}$ & $\begin{array}{c}\text { Relative } \\
\text { Error/\% }\end{array}$ \\
\hline 250 & 431 & 436 & -1.16 & 11.28 & 11.52 & -2.13 \\
280 & 429 & 440 & -2.56 & 11.28 & 10.92 & 3.21 \\
330 & 429 & 435 & -1.40 & 11.84 & 11.63 & 1.77 \\
400 & 435 & 422 & 3 & 12.1 & 11.83 & 2.63 \\
\hline
\end{tabular}

\section{Results and Discussion}

\subsection{Effect of Angle of Deflector}

By adjusting the angle of the deflector, the flue gas flow field can be changed, thereby affecting the evaporation characteristics of the desulfurization wastewater droplets. In this work, the angles of the inner and outer deflectors are set as $0^{\circ}, 15^{\circ}, 30^{\circ}$ and $45^{\circ}$, respectively, to investigate the changes of the flow field and the evaporation condition of the droplets. Due to the large temperature difference and relative velocity between the droplets and flue gas when they are just in contact, the evaporation rate of the droplets is large. Therefore, the flow field distribution near the outlet of the hot air distributor has an important influence on the evaporation characteristics of the droplets.

Figure 6 shows the effect of different inner deflectors angles on the flow field at the outer deflector angle of $0^{\circ}$. It can be seen that flue gas streamlines are basically vertical 
downward, when the angle is $0^{\circ}$. Where there is a high-speed zone around the atomizer, the reason is that the velocity of droplet injection is higher, which enhances the flue gas velocity. With the angle increasing, the flue gas streamlines form a certain angle with the axis, forming a spiral-down gas flow inside the desiccator. This means that the flue gas can stay longer in there and, then, have a longer contact time with the droplets, which is beneficial to the evaporation of the droplets. The partial enlargement view from Figure 6 shows the details of the streamline. The internal streamline presents a spiral trend, while the outer streamline is basically vertical downwards, which suppresses the swirling effect of the gas to a certain extent.

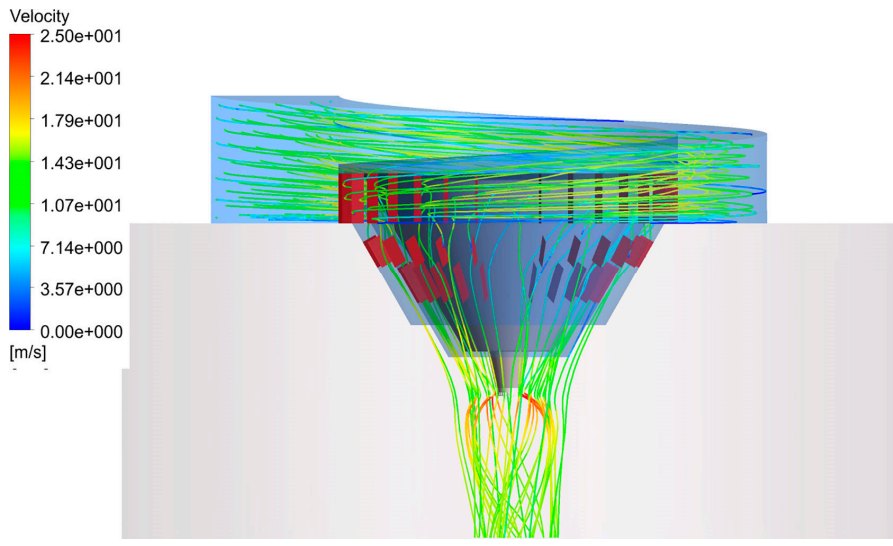

(a)

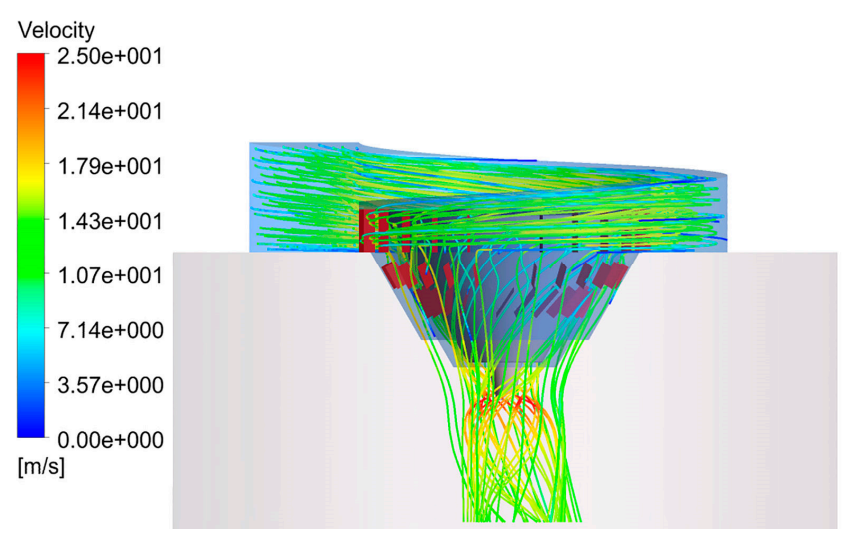

(c)

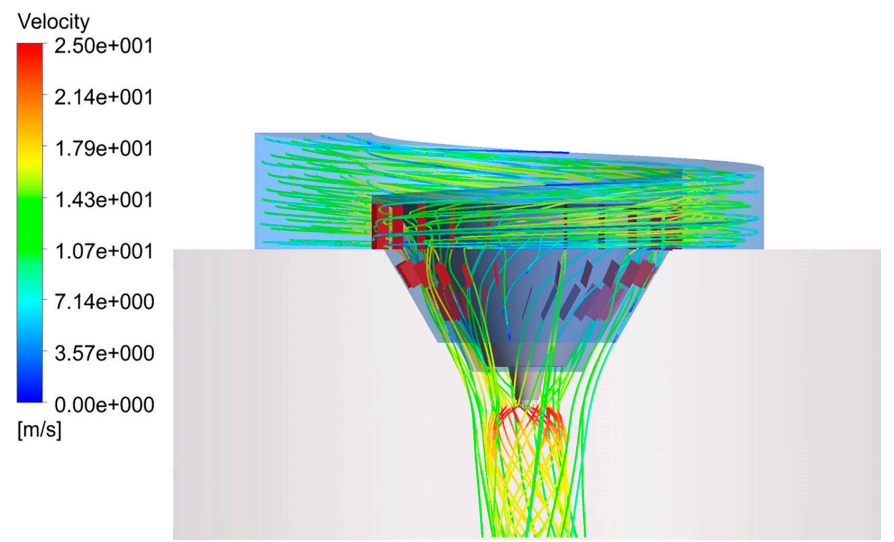

(b)

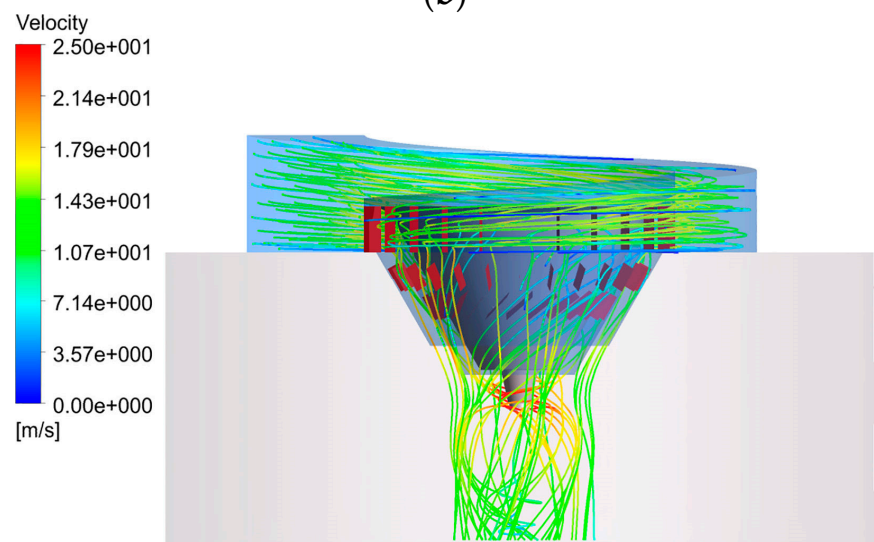

(d)

Figure 6. Outlet flue gas streamlines of the hot air distributor at different inner deflector angles: (a) $0^{\circ}$; (b) $15^{\circ}$; (c) $30^{\circ}$; (d) $45^{\circ}$.

The effects of different outer deflector angles on the flow field at the inner deflector angle of $0^{\circ}$ are shown in Figure 6. With the increase in the angle, the flue gas forms a stronger spiral gas flow inside the desiccator, which is similar to the law shown in Figure 7. Moreover, it also shows that the same angle of the outer panel is able to generate airflow with greater spiral strength, relative to the inner panel, in contrast to Figure 7 . Therefore, increasing the outer diffuser angle may be preferred, when considering enhanced flue gas swirling. 


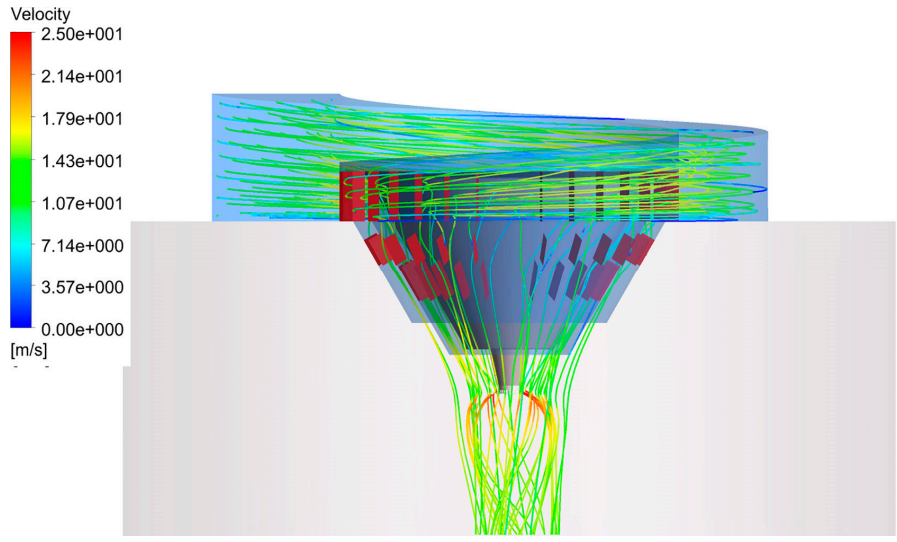

(a)

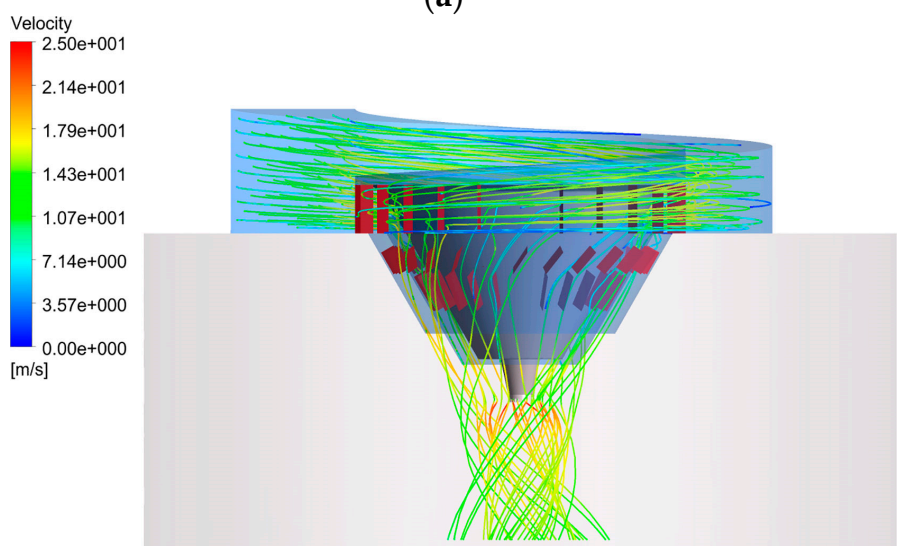

(c)

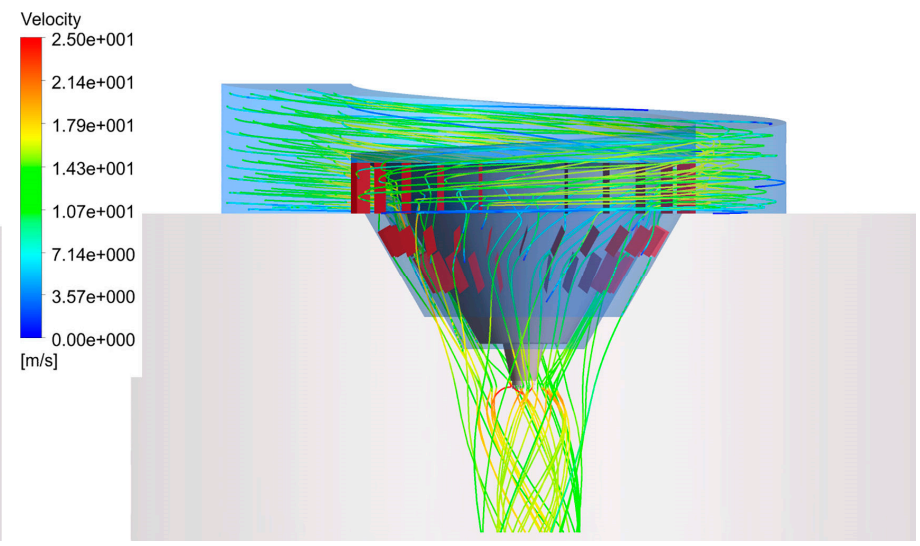

(b)

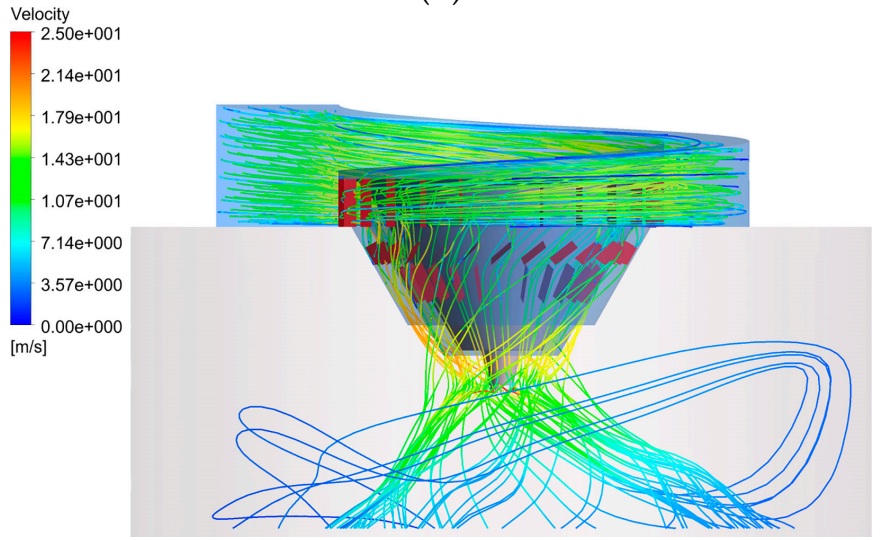

(d)

Figure 7. Outlet flue gas streamlines of the hot air distributor at different outer deflector angles: (a) $0^{\circ}$; (b) $15^{\circ}$; (c) $30^{\circ}$; (d) $45^{\circ}$.

Figure 8 presents the variation of mean evaporation time of the droplets at different angles of the inner and outer deflectors. The mean evaporation time of the droplets decreases with increasing the angle of deflectors. This is because the flue gas changes direction to spiral down after passing through the inclined deflectors, which increases the relative velocity between gas and liquid and, then, the evaporation rate of droplets. Since flue gas entering from the inner layer of the flue gas splitter is first in contact with the droplets, at which point the temperature difference and relative velocity between gas and liquid are the largest, that is, the rate of heat transfer is the largest, changing the angle of the inner deflectors has a greater effect on the evaporation rate of the droplets under the same circumstances. In addition, because the momentum of the droplets is relatively small, the movement of the droplets is more influenced by the flue gas and the relative velocity decreases rapidly, resulting in the evaporation time of the droplets not changing significantly with the angle of the deflectors.

The effect of the angle of the deflectors on the average axial evaporation distance of the droplets can be seen in Figure 9. Compared to the vertical plates (both $0^{\circ}$ ), when the angle of the inner and outer deflectors is changed from $0^{\circ}$ to $45^{\circ}$, the average axial evaporation distance of the droplets is shortened by $1.3 \mathrm{~m}$ and $1.1 \mathrm{~m}$, respectively, which illustrates that increasing the angle of the deflectors appropriately allows the droplets to evaporate at a shorter axial distance. Because the droplets first contact with flue gas at the outlet of the inner layer of the splitter, increasing its evaporation rate, the change of the angle of the inner deflectors has a greater impact. 


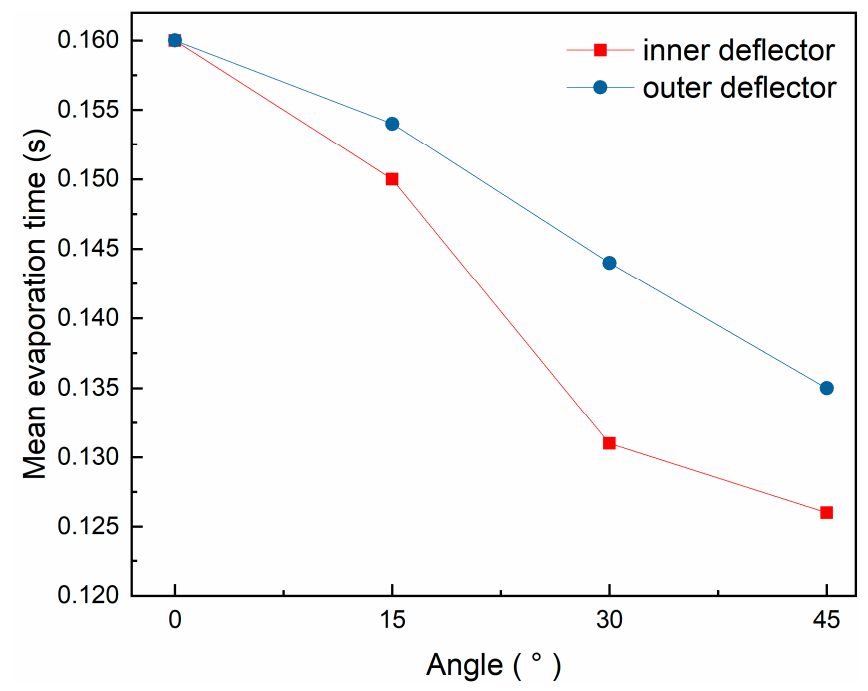

Figure 8. Variation of mean evaporation time with angle of deflector.

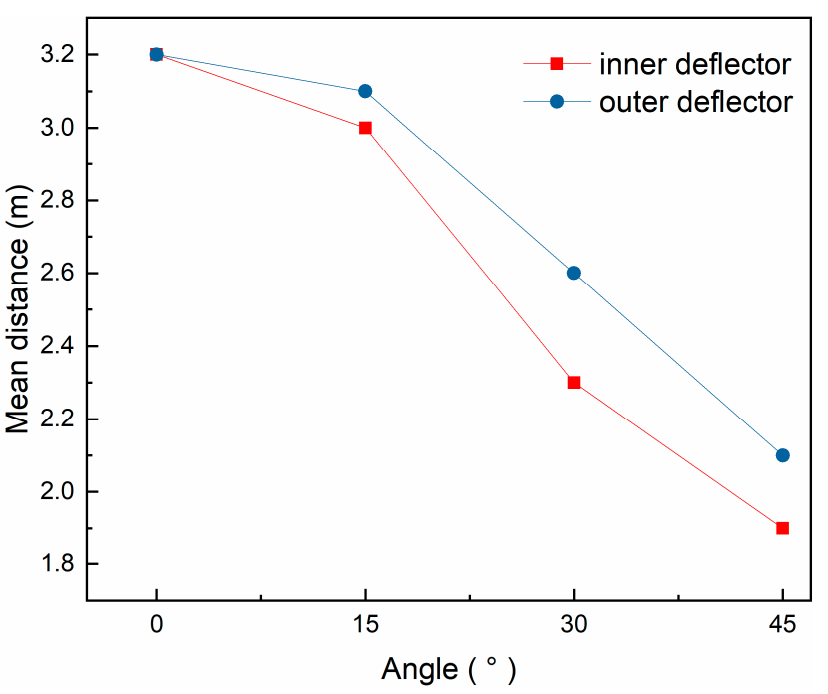

Figure 9. Variation of mean axial distance with angle of deflector.

\subsection{Effect of Gas-Liquid Ratio}

In actual operation, because of the frequent changes in power plant load, the wastewater treatment volume of the drying tower also changes accordingly. When the flue gas volume is $30,000 \mathrm{Nm}^{3} / \mathrm{h}$, the wastewater treatment volume is set to $3.61,3.23,3$ and $2.61 \mathrm{~m}^{3} / \mathrm{h}$, respectively, and the gas-liquid ratio is $8300,9300,10,000$ and $11,500 \mathrm{~m}^{3} / \mathrm{Nm}^{3}$.

Figure 10 shows the temperature distribution at different gas-liquid ratios. The temperature of flue gas in the hot air distributor is the highest $(613 \mathrm{~K})$. When the hot gas contacts the wastewater droplets around the atomizer, the temperature drops rapidly. In Figure $10 \mathrm{a}, \mathrm{b}$, there is an obvious low temperature area under the atomizer, indicating that there is a strong phenomenon of heat and mass transfer, which is the main evaporation area of the droplet. With the increase in the gas-liquid ratio, the corresponding hot smoke volume per unit number of droplets increases, the temperature in the dryer increases gradually and the low temperature area is smaller and smaller. When the gas-liquid ratio is $8300,9300,10,000$ and $11,500 \mathrm{~m}^{3} / \mathrm{Nm}^{3}$, the outlet temperature of the dryer is $389.8,406.8,423$ and $446.2 \mathrm{~K}$, respectively. In addition, the temperature distribution of the lower part of the dryer is uniform under four cases, which proves that the water has completely evaporated. 


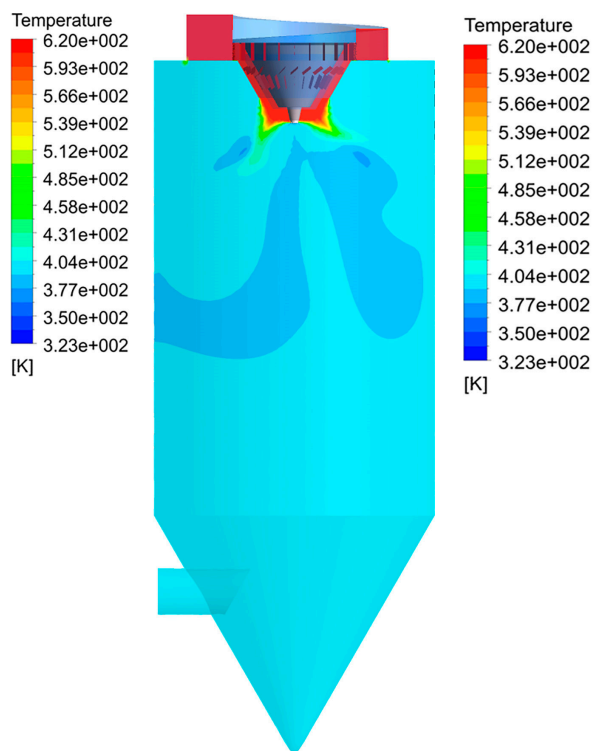

(a)

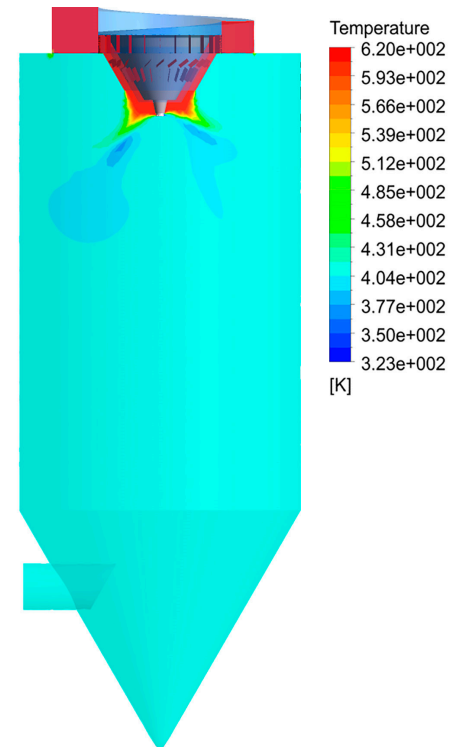

(b)

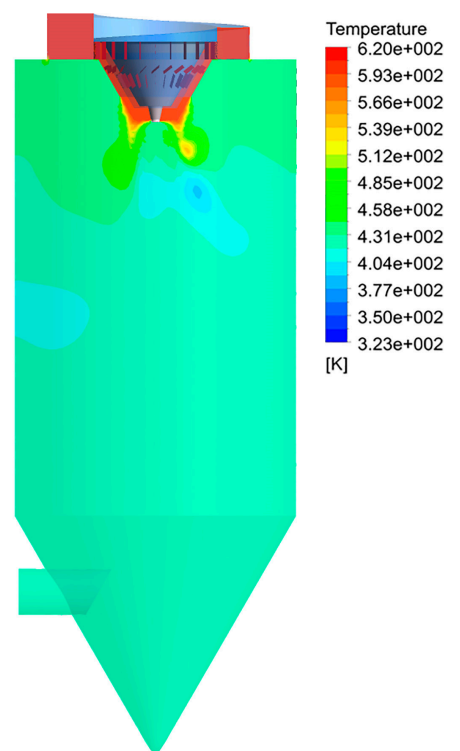

(c)

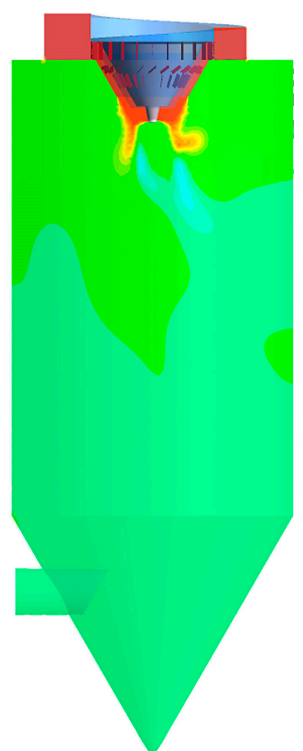

(d)

Figure 10. Temperature field distribution with different gas-liquid ratios: (a) $8300 \mathrm{~m}^{3} / \mathrm{Nm}^{3}$; (b) $9300 \mathrm{~m}^{3} / \mathrm{Nm}^{3}$; (c) 10,000 $\mathrm{m}^{3} / \mathrm{Nm}^{3} ;$ (d) $11,500 \mathrm{~m}^{3} / \mathrm{Nm}^{3}$.

The mean time and axial distance required for the complete evaporation of the droplets are shown in Figure 11 under different gas-liquid ratios. As the gas-liquid ratio decreases, the evaporation time and distance of the droplets show a similar increasing trend, but the increasing amplitude gradually decreases. On the one hand, with the decrease in desulfurization wastewater flow rate, the amount of hot flue gas corresponding to a unit number of droplets increases, which increases the heat and mass transfer rate between gas and liquid, thus promoting the evaporation effect of droplets. On the other hand, the lower the flow of desulfurization wastewater, the greater the flue gas resistance of the droplets and the faster the relative velocity attenuation, which hinders the further improvement of its evaporation efficiency. When the wastewater treatment volume is less than $3 \mathrm{~m}^{3} / \mathrm{h}$, the increase in gas-liquid ratio has similar promoting and inhibiting effects on evaporation efficiency, resulting in little change in evaporation time and distance.

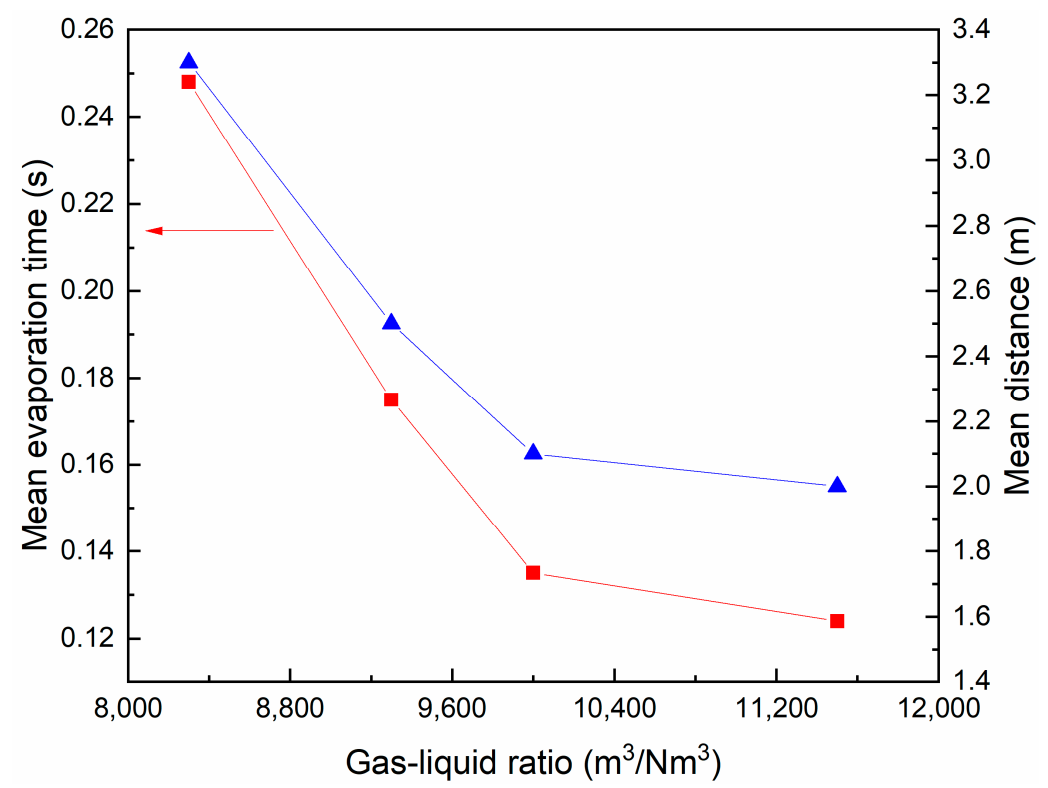

Figure 11. Variation of mean evaporation time and axial distance with gas-liquid ratio. 
The curves of droplet percentage changing with mean evaporation time at different gas-liquid ratios are shown in Figure 12. It can be clearly seen that the change trend of the evaporation percentage curve of each droplet is similar. In the initial stage $(<0.02 \mathrm{~s})$, the rate of droplet evaporation was rapid and the evaporation percentages all exceeded $20 \%$. With the extension of mean evaporation time, the growth trend of the curve slowed down and the evaporation rate corresponding to the droplets gradually decreased. This phenomenon depends on the temperature difference and relative velocity, which are larger when the droplets just evaporate, between droplets and flue gas, implying a greater heat and mass transfer rate between the gas phase and the liquid phase. It can also be seen, from Figure 12, that when the mean evaporation time is the same, the droplet evaporation percentage increases as the gas-liquid ratio increases.

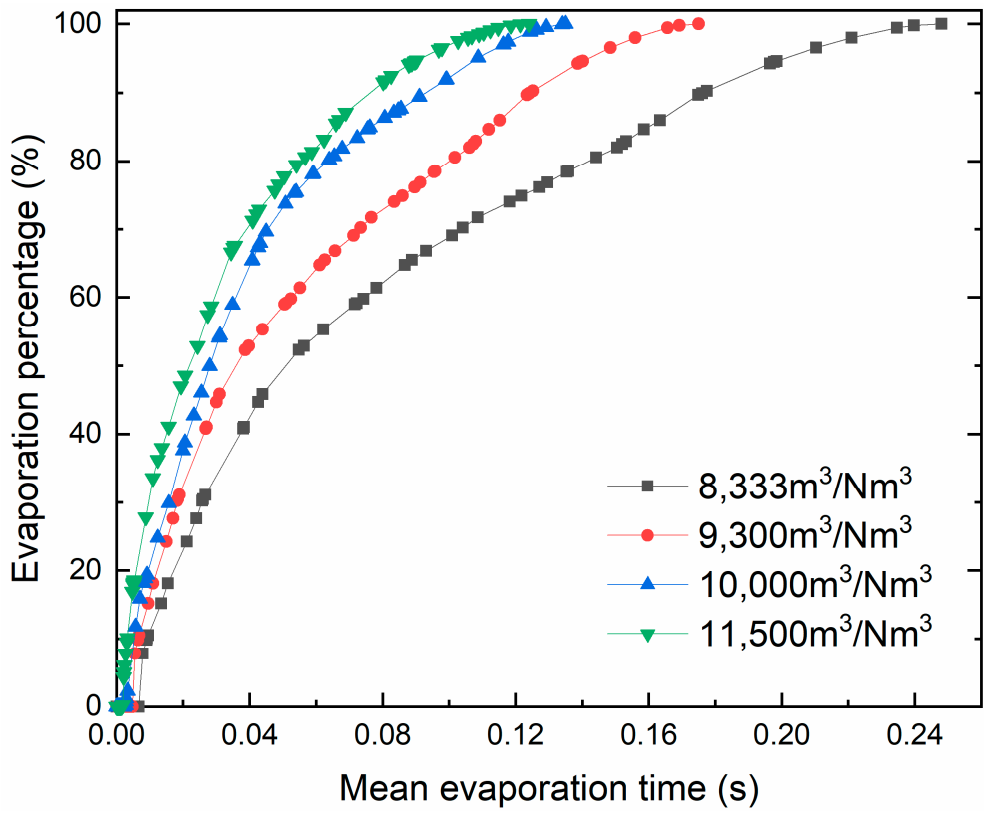

Figure 12. Variation of droplet evaporation percentage with mean evaporation time under different gas-liquid ratios.

The trajectories of the droplets under different gas-liquid ratios are shown in Figure 13. When the gas-liquid ratio is low, the trajectories of the droplets are umbrella-shaped and spread downward. The higher the gas-liquid ratio, the more the trajectories shrink inward. The reason is that, under the influence of centrifugal force and flue gas resistance, the droplet performs a parabolic-like motion in the initial stage. Then, they spiral downward along with the flue gas. A higher gas-liquid ratio means that the flue gas resistance per unit number of droplets increases and it is easier to move with the flue gas during the evaporation process. Appropriately reducing the gas-liquid ratio can improve the operating efficiency of the dryer, but a too low gas-liquid ratio will cause the droplets to evaporate longer in the axial direction, causing them to hit the wall. For instance, when the gas-liquid ratio is $8300 \mathrm{~m}^{3} / \mathrm{Nm}^{3}, 0.11 \%$ of the droplets are captured by the wall, which shows that the inner wall of the dryer may be corroded under these working conditions. Therefore, the suitable gas-liquid ratio is $9300 \mathrm{~m}^{3} / \mathrm{Nm}^{3}$. 


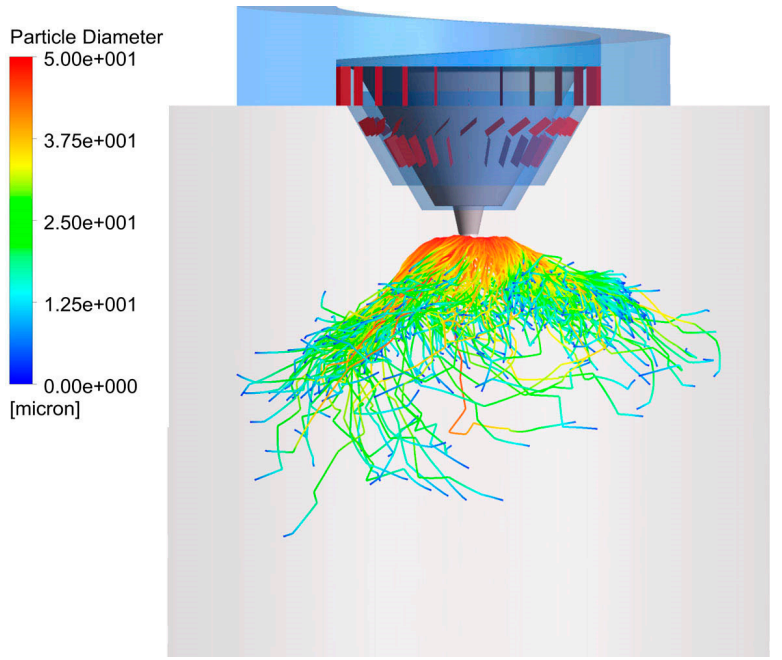

(a)

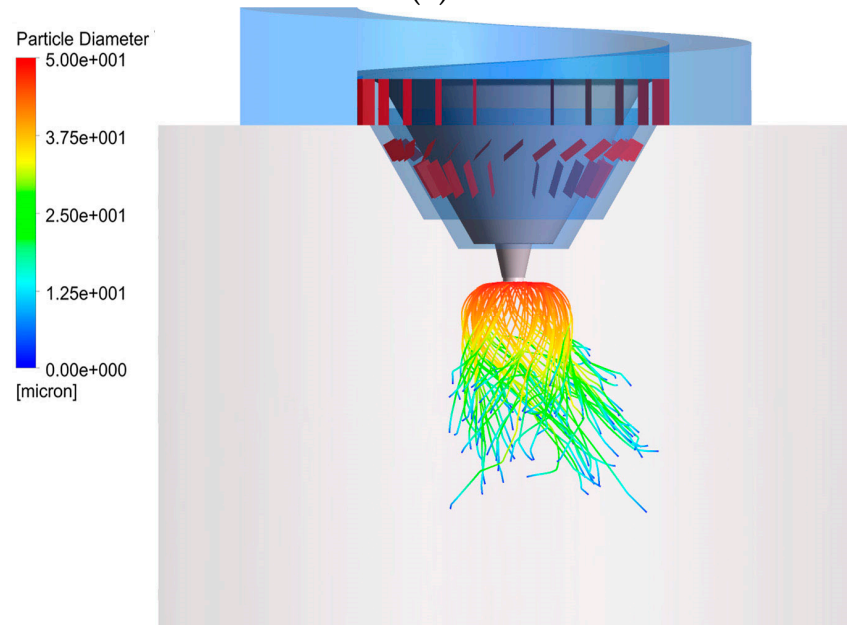

(c)

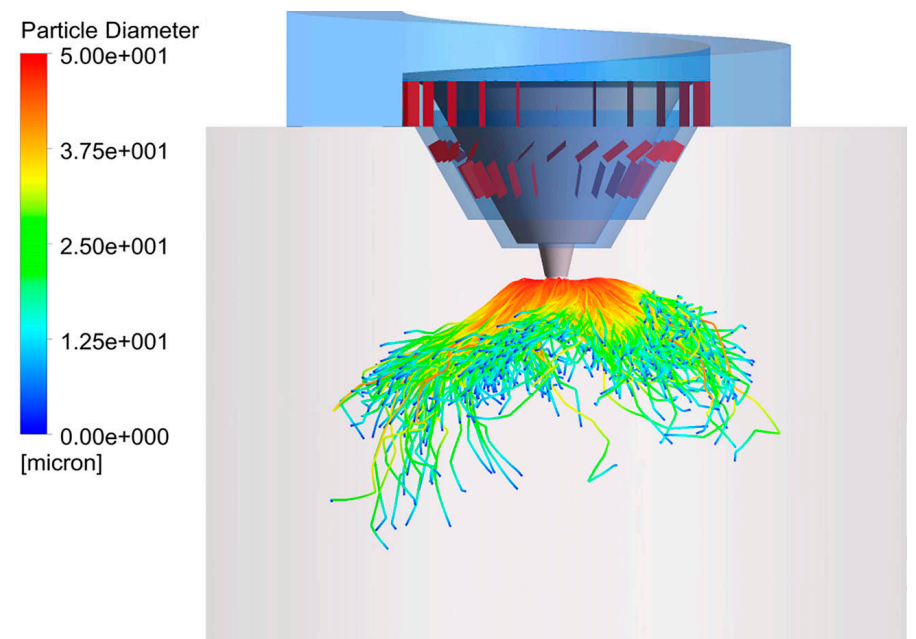

(b)

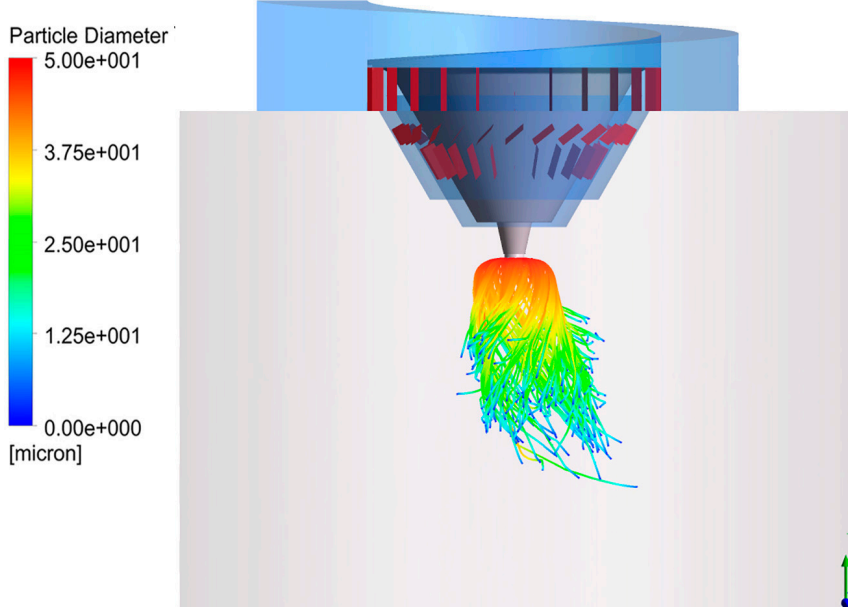

(d)

Figure 13. Droplet trajectories with different gas-liquid ratios: (a) $8300 \mathrm{~m}^{3} / \mathrm{Nm}^{3}$; (b) $9300 \mathrm{~m}^{3} / \mathrm{Nm}^{3}$; (c) $10,000 \mathrm{~m}^{3} / \mathrm{Nm}^{3}$; (d) $11,500 \mathrm{~m}^{3} / \mathrm{Nm}^{3}$.

\subsection{Effect of Rotational Speed}

The atomizer is an important part of the dryer and its rotational speed is an important factor that affects the evaporation effect of the atomized droplets. Based on the gas-liquid ratio of $9300 \mathrm{~m}^{3} / \mathrm{Nm}^{3}$, the cases of 13,000,16,000, 19,000 and 22,000 rpm were simulated, respectively. Figure 14 shows the $\mathrm{H}_{2} \mathrm{O}$ concentration field distribution at different rotational speeds. In Figure 13a-d, the $\mathrm{H}_{2} \mathrm{O}$ concentration increases rapidly and distributes uniformly after the hot flue gas contacts the droplets. It can be seen, from Figure 14a, that there is an obvious high concentration area under the outlet of the hot air distributor. This is because the droplet evaporation area is more concentrated at low rotation speed, resulting in higher concentration. With the increase in rotational speed, the low temperature region gradually decreases until it disappears. 


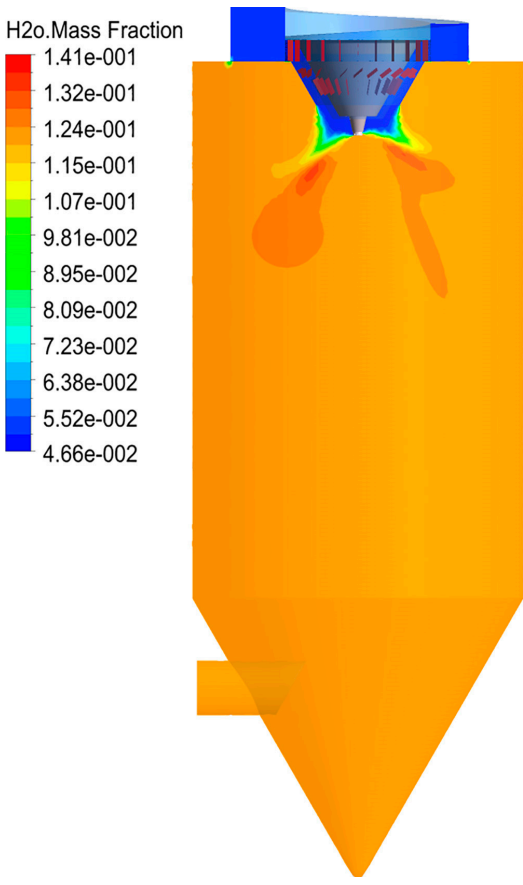

(a)

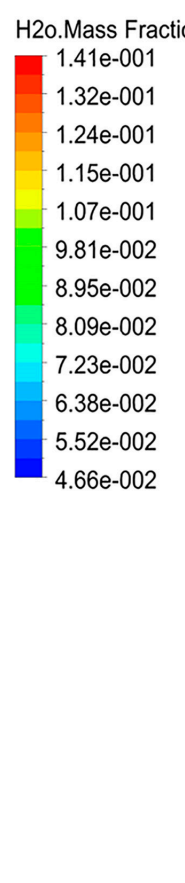

(b)
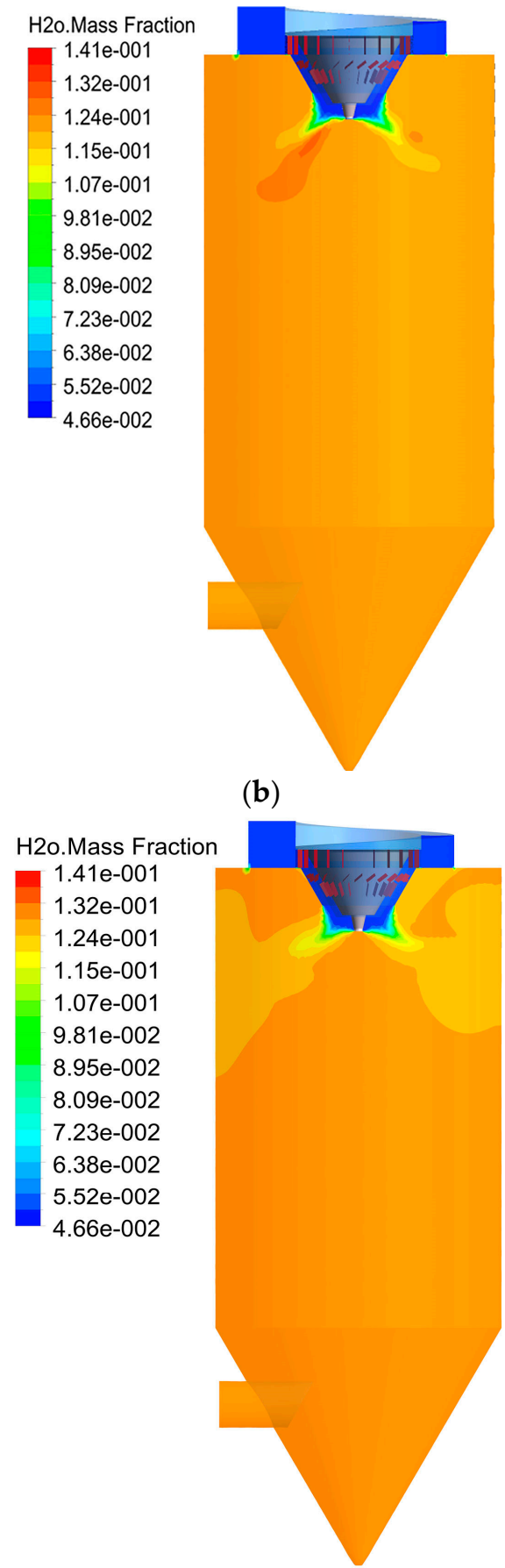

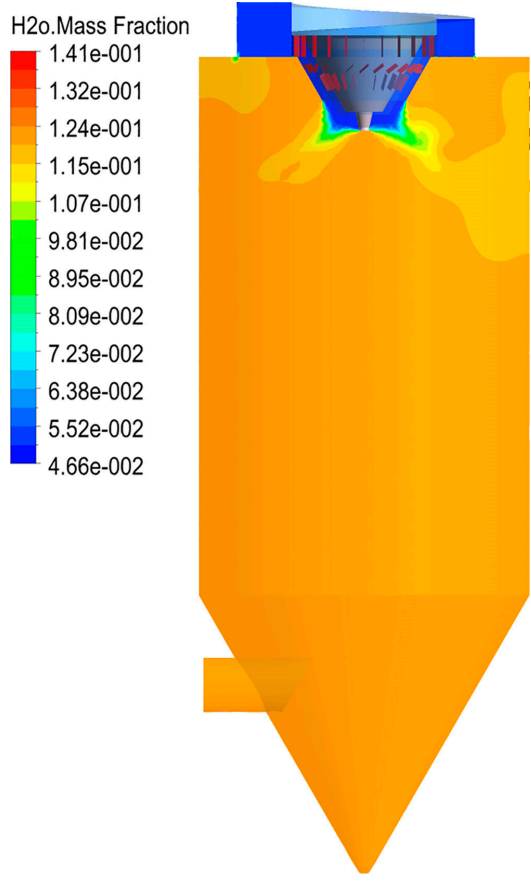

(c)

(d)

Figure 14. $\mathrm{H}_{2} \mathrm{O}$ concentration field distribution with different rotational speeds: (a) 13,000 rpm; (b) 16,000 rpm; (c) 19,000 rpm; (d) 22,000 rpm.

The effect of rotational speed on the average time and axial distance required for the complete evaporation of the droplets is shown in Figure 15. As the rotational speed increases, the average evaporation time and axial distance of the droplets decrease. When the rotational speed is increased from 13,000 rpm to 22,000 rpm, the evaporation time and axial distance are reduced by $16.14 \%$ and $22.7 \%$, respectively. This is because increasing the rotational speed enables the atomized droplets to obtain a higher initial speed, which increases the relative speed between gas and liquid, strengthens the convection heat transfer inside the dryer and promotes the evaporation of droplets. Moreover, the higher initial velocity means that the rigidity of droplets is stronger and the downward 
velocity component is smaller, so that the droplet evaporates completely within a shorter axial distance.

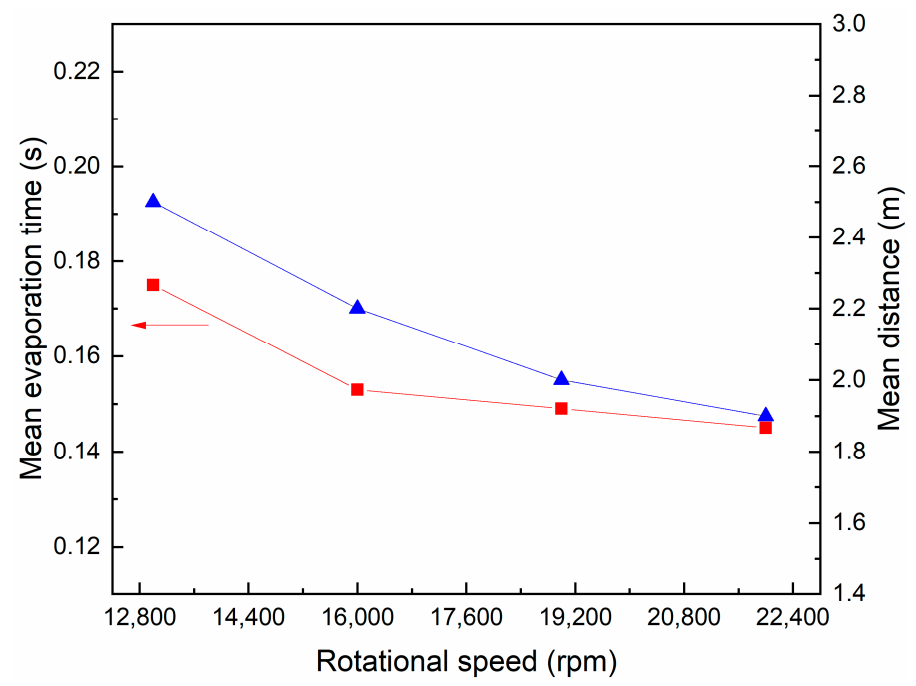

Figure 15. Variation of mean evaporation time and axial distance with rotational speed.

The changing curves of the evaporation percentage of the droplets are shown in Figure 16 under different rotational speeds with mean evaporation time. At the same time, the evaporation percentage of the droplets increases with the increase in the rotational speed, indicating that the evaporation rate of the droplets has improved. The main reason is that increasing the rotational speed of the atomizer can increase the initial relative velocity of small droplets with flue gas, thus improving the convective heat transfer efficiency. In addition, the droplet particle size decreases with increasing evaporation time, resulting in a decrease in the specific surface area, which impedes the evaporation of the droplets to some extent, as evident from the curve changing trend of Figure 16.

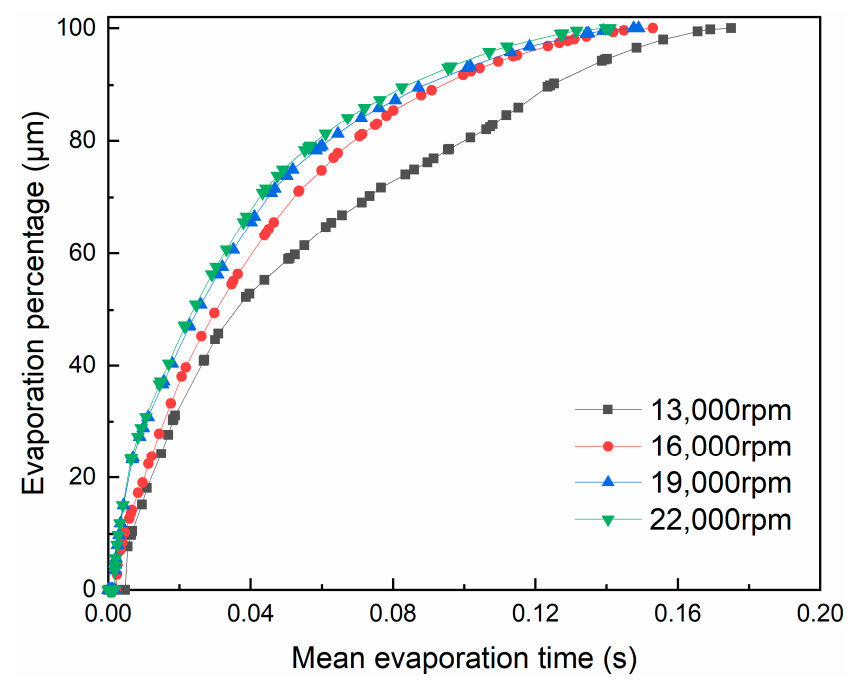

Figure 16. Variation of droplet evaporation percentage with mean evaporation time under different rotational speeds.

It can also be seen, from Figure 16, that, when the rotational speed is greater than $16,000 \mathrm{rpm}$, the average time required for the complete evaporation of the droplets is basically unchanged. The reason is that the higher the rotational speed, the faster the droplet size reduction rate. As the specific surface area of the droplets becomes smaller, the evaporation rate decreases. At the same time, in conjunction with the droplet trajectory shown in Figure 17, it can be seen that a higher rotational speed (over 19,000 rpm) causes 
some droplets to leave the main evaporation zone, which, instead, limits the shortening of the evaporation time. In addition, $0.15 \%$ of droplets adhere to the inner wall in these working conditions, which is likely to cause corrosion problems. In summary, the droplet evaporation effect is better when the rotational speed is $16,000 \mathrm{rpm}$.
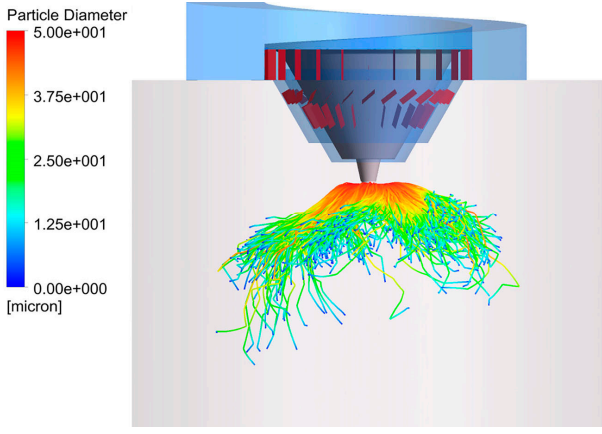

(a)

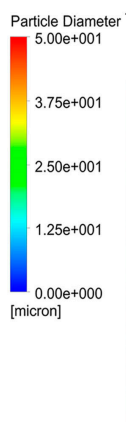

Particle Diame
$\begin{aligned} & 5.00 \mathrm{e}+001 \\ & 3.75 \mathrm{e}+001 \\ & 2.50 \mathrm{e}+001 \\ & 1.25 \mathrm{e}+001 \\ & 0.000+000 \\ & \text { [micron] }\end{aligned}$

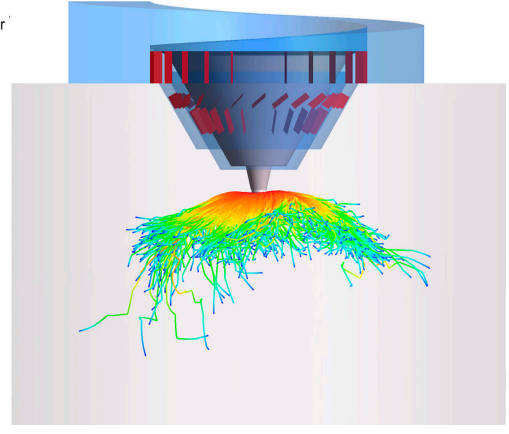

(b)
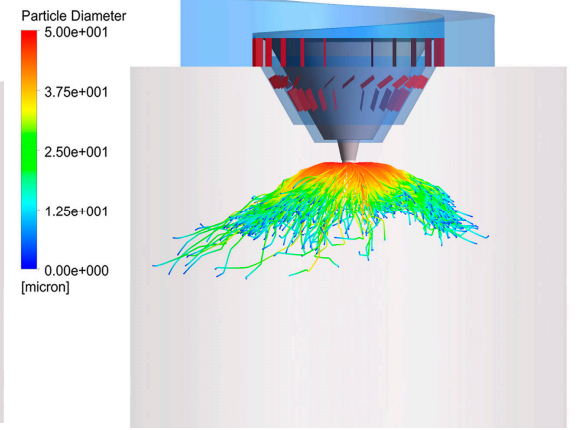

(c)

(d)

Figure 17. Droplet trajectories with different rotational speeds: (a) 13,000 rpm; (b) 16,000 rpm; (c) 19,000 rpm; (d) 22,000 rpm.

\section{Conclusions}

A simulation study of centrifugal spray drying was carried out in the desulphurization wastewater dryer of a $330 \mathrm{MW}$ power plant. Through reliability verification, it is found that the simulation results are in good agreement with the actual measurement results, which proves that the numerical model can accurately reflect the actual operating conditions. This study draws the following conclusions:

(1) The angle of the deflectors has a great influence on the flue gas flow field in the spray dryer. As the angle increases, the swirling effect of the airflow becomes stronger. In the same situation, the influence of increasing the angle of the outer deflectors is more obvious than that of the inner one.

(2) Increasing the angle of the deflectors can effectively shorten the mean time and axial distance required for the complete evaporation of the droplets. Among them, the change in the angle of the inner deflectors has a greater impact on the droplet evaporation effect.

(3) The flue gas forms a high-speed area under the outlet of the hot air distributor and most of the liquid droplets evaporate in this area. As the gas-liquid ratio decreases, the high-speed zone expands radially, showing an umbrella shape.

(4) The mean time and axial distance required for complete evaporation of droplets increase with the decrease in the gas-liquid ratio and the increasing amplitude gradually decreases. When the gas-liquid ratio is $8300 \mathrm{~m}^{3} / \mathrm{Nm}^{3}, 0.11 \%$ of the droplets are captured by the wall, which is likely to cause corrosion problems. Thus, the best gas-liquid ratio is $9300 \mathrm{~m}^{3} / \mathrm{Nm}^{3}$.

(5) Increasing the rotational speed of the atomizer is conducive to shortening the mean evaporation time and axial distance of droplets to a certain extent, but excessive rotational speed may cause the droplets to adhere to the wall. The results show that $16,000 \mathrm{rpm}$ is the optimum rotational speed. 
Author Contributions: Conceptualization, N.Z. and Z.L.; methodology, N.Z.; software, Z.L. and Y.F.; validation, N.Z. and Y.F.; formal analysis, N.Z.; investigation, N.Z. and Y.F.; resources, Z.L., Y.F. and D.L.; data curation, N.Z.; writing—original draft preparation, N.Z.; writing—review and editing, Z.L., D.L. and Y.F.; visualization, Z.L.; supervision, D.L.; project administration, N.Z. and D.L.; funding acquisition, N.Z. All authors have read and agreed to the published version of the manuscript.

Funding: This research was funded by Critical Technology Research and Integrated Application for Wastewater Resources and Zero Emission in High Water Consumption Enterprises (GDKJXM20183546).

Institutional Review Board Statement: Not applicable.

Informed Consent Statement: Not applicable.

Data Availability Statement: Data is contained within the article.

Acknowledgments: The support from the Guangdong Key Laboratory of Efficient and Clean Energy Utilization at South China University of Technology, China, is gratefully acknowledged.

Conflicts of Interest: The authors declare no conflict of interest.

\section{Nomenclature}

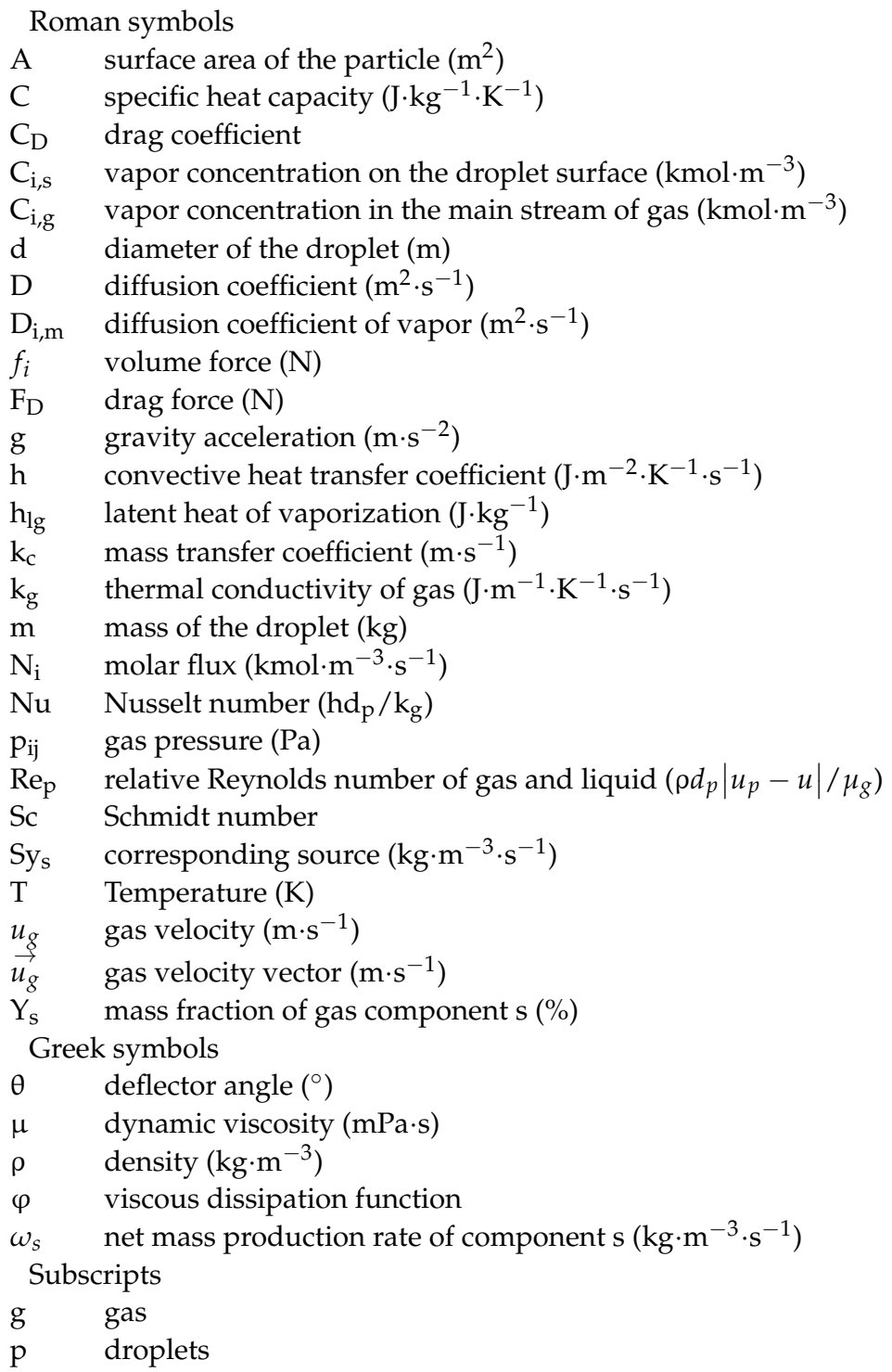




\section{References}

1. Cui, W.; Li, J.; Xu, W.; Güneralp, B. Industrial electricity consumption and economic growth: A spatio-temporal analysis across prefecture-level cities in China from 1999 to 2014. Energy 2021, 222, 119932. [CrossRef]

2. Suganthi, L.; Samuel, A.A. Energy models for demand forecasting-A review. Renew. Sustain. Energy Rev. 2012, 16, 1223-1240. [CrossRef]

3. Wu, C.; Oh, K.; Long, X.; Zhang, J. Effect of installed capacity size on environmental efficiency across 528 thermal power stations in North China. Environ. Sci. Pollut. Res. 2019, 26, 29822-29833. [CrossRef]

4. Chen, S.; Li, Y.; Yao, Q. The health costs of the industrial leap forward in China: Evidence from the sulfur dioxide emissions of coal-fired power stations. China Econ. Rev. 2018, 49, 68-83. [CrossRef]

5. Han, L.; Zhou, W.; Li, W.; Qian, Y. Urbanization strategy and environmental changes: An insight with relationship between population change and fine particulate pollution. Sci. Total. Environ. 2018, 642, 789-799. [CrossRef]

6. Iii, R.L.M.; Berndt, T.; Sipilä, M.; Paasonen, P.; Petäjä, T.; Kim, S.; Kurtén, T.; Stratmann, F.; Kerminen, V.-M.; Kulmala, M. A new atmospherically relevant oxidant of sulphur dioxide. Nat. Cell Biol. 2012, 488, 193-196. [CrossRef]

7. Córdoba, P. Status of Flue Gas Desulphurisation (FGD) systems from coal-fired power plants: Overview of the physic-chemical control processes of wet limestone FGDs. Fuel 2015, 144, 274-286. [CrossRef]

8. Córdoba, P. Partitioning and speciation of selenium in wet limestone flue gas desulphurisation systems: A review. Fuel 2017, 202, 184-195. [CrossRef]

9. Shuangchen, M.; Jin, C.; Gongda, C.; Weijing, Y.; Sijie, Z. Research on desulfurization wastewater evaporation: Present and future perspectives. Renew. Sustain. Energy Rev. 2016, 58, 1143-1151. [CrossRef]

10. Chen, S.-T.; Wickramasinghe, S.; Qian, X. High Performance Mixed-Matrix Electrospun Membranes for Ammonium Removal from Wastewaters. Membranes 2021, 11, 440. [CrossRef]

11. Ng, S.M.; Idrus, S.; Ahsan, A.; Marzuki, T.T.M.; Mahat, S. Treatment of Wastewater from a Food and Beverage Industry Using Conventional Wastewater Treatment Integrated with Membrane Bioreactor System: A Pilot-Scale Case Study. Membranes 2021, 11, 456. [CrossRef]

12. Shi, Y.; Wang, Z.; Du, X.; Gong, B.; Jegatheesan, V.; Haq, I. Recent Advances in the Prediction of Fouling in Membrane Bioreactors. Membranes 2021, 11, 381. [CrossRef] [PubMed]

13. Higgins, T.E.; Sandy, A.T.; Givens, S.W. Flue Gas Desulfurization Wastewater Treatment Primer; OSTI: Oak Ridge, TN, USA, 2009.

14. Wales, M.; Gebremichael, E.; Wang, X.; Perea, E.; Jayaweera, P.; Jayaweera, I. Flue Gas Desulfurization (FGD) Wastewater Treatment Using Polybenzimidazole (PBI) Hollow Fiber (HF) Membranes. Membranes 2021, 11, 430. [CrossRef]

15. Ali, M. Nanofiltration Process for Enhanced Treatment of RO Brine Discharge. Membranes 2021, 11, 212. [CrossRef] [PubMed]

16. Yang, F.; Huang, Z.; Huang, J.; Wu, C.; Zhou, R.; Jin, Y. Tanning Wastewater Treatment by Ultrafiltration: Process Efficiency and Fouling Behavior. Membranes 2021, 11, 461. [CrossRef] [PubMed]

17. Beaulieu, M.; Perreault, V.; Mikhaylin, S.; Bazinet, L. How Overlimiting Current Condition Influences Lactic Acid Recovery and Demineralization by Electrodialysis with Nanofiltration Membrane: Comparison with Conventional Electrodialysis. Membranes 2020, 10, 113. [CrossRef]

18. Jia, F.; Wang, J. Treatment of flue gas desulfurization wastewater with near-zero liquid discharge by nanofiltration-membrane distillation process. Sep. Sci. Technol. 2017, 53, 146-153. [CrossRef]

19. Liang, Z.; Cheng, X.; Zhang, L.; Yang, Z.; Ran, J.; Ding, L. Study of Main Solutes on Evaporation and Crystallization Processes of the Desulfurization Wastewater Droplet. Energy Fuels 2018, 32, 6119-6129. [CrossRef]

20. Teng, X. A Pilot Demonstration of Spray Dryer Evaporation as a Method to Treat Power Plant FGD Wastewater; Southern Company: Birmingham, UK, 2012.

21. Ma, S.; Chai, J.; Wu, K.; Wan, Z.; Xiang, Y.; Zhang, J.; Fan, Z. Experimental and mechanism research on volatilization characteristics of $\mathrm{HCl}$ in desulfurization wastewater evaporation process using high temperature flue gas. J. Ind. Eng. Chem. 2018, 66, 311-317. [CrossRef]

22. Ma, S.; Chai, J.; Wu, K.; Xiang, Y.; Jia, S.; Li, Q. Experimental research on bypass evaporation tower technology for zero liquid discharge of desulfurization wastewater. Environ. Technol. 2018, 40, 2715-2725. [CrossRef] [PubMed]

23. Ceidk, P.; Flikova, I. Some Aspects of Spray Formation by Pneumatic Nozzles. Dry. Technol. 1985, 3, 101-118. [CrossRef]

24. Liang, Z.; Zhang, L.; Yang, Z.; Qiang, T.; Pu, G.; Ran, J. Evaporation and crystallization of a droplet of desulfurization wastewater from a coal-fired power plant. Appl. Therm. Eng. 2017, 119, 52-62. [CrossRef]

25. Kim, H.; Sung, N. The effect of ambient pressure on the evaporation of a single droplet and a spray. Combust. Flame 2003, 135, 261-270. [CrossRef]

26. Huang, L.; Kumar, K.; Mujumdar, A.S. Use of Computational Fluid Dynamics to Evaluate Alternative Spray Dryer Chamber Configurations. Dry. Technol. 2003, 21, 385-412. [CrossRef]

27. Huang, L.X.; Passos, M.L.; Kumar, K.; Mujumdar, A.S. A Three-Dimensional Simulation of a Spray Dryer Fitted with a Rotary Atomizer. Dry. Technol. 2005, 23, 1859-1873. [CrossRef]

28. Zhang, S.; Liu, N.; Pan, Y.; Wang, W.; Li, Y.; Zhu, Y. Three-dimensional modelling of two-phase flow and transport in a pilot centrifugal spray dryer. Chem. Phys. Lett. 2021, 765, 138309. [CrossRef]

29. Ye, X.; Zhang, C.; Wang, S.; Yang, D.; Guo, B.; An, X.; Yu, A. Simulation of desulphurization wastewater evaporation through flue gas. Powder Technol. 2020, 361, 462-472. [CrossRef] 
30. Gradinger, T.; Boulouchos, K. A zero-dimensional model for spray droplet vaporization at high pressures and temperatures. Int. J. Heat Mass Transf. 1998, 41, 2947-2959. [CrossRef]

31. Ma, S.; Feng, C.; Wu, W.; Hua, J.; Yu, W.J.C.; Chemistry, A. The numerical simulation of flue gas desulphurization wastewater spray evaporation. Comput. Appl. Chem. 2016, 33, 47-53.

32. Zhang, H. Numerical research on a vaporizing fuel droplet in a forced convective environment. Int. J. Multiph. Flow 2004, 30, 181-198. [CrossRef]

33. Javed, K.; Mahmud, T.; Purba, E. Enhancement of Mass Transfer in a Spray Tower Using Swirling Gas Flow. Chem. Eng. Res. Des. 2006, 84, 465-477. [CrossRef]

34. Wilson, M.; Pilbrow, R.; Owen, J.M. Flow and Heat Transfer in a Preswirl Rotor-Stator System. J. Turbomach. 1997, 119, 364-373. [CrossRef]

35. Jubaer, H.; Afshar, S.; Le Maout, G.; Mejean, S.; Selomulya, C.; Xiao, J.; Chen, X.D.; Jeantet, R.; Woo, M.W. The impact of self-sustained oscillations on particle residence time in a commercial scale spray dryer. Powder Technol. 2020, 360, 1177-1191. [CrossRef]

36. Wu, Y.H.; Yu, X.; Siew, P.F. Numerical Simulation of Fluid-Solid Two-Phase Flows at Particle Level. In Advances in Scientific Computing and Applications; Science Press: Beijing, China, 2004.

37. Villars, P.; Cenzual, K.; Gladyshevskii, R. Handbook of Inorganic Substances; De Gruyter: Berlin, Germany, 2015, ISBN 101515/9783110311747. 